\title{
The flagellin-TLR5-Nox4 axis promotes the migration of smooth muscle cells in atherosclerosis
}

\author{
Jinoh Kim', Jung-Yeon Yoo ${ }^{1}$, Jung Min Suh', Sujin Park', Dongmin Kang ${ }^{1}$, Hanjoong Jo $\mathbb{C}^{2}$ and Yun Soo Bae
}

\begin{abstract}
We hypothesized that NADPH oxidase 4 (Nox4) is involved in the formation of neointimal atherosclerotic plaques through the migration of smooth muscle cells (SMCs) in response to flagellin. Here, we demonstrate that TLR5mediated Nox4 activation regulates the migration of SMCs, leading to neointimal plaque formation in atherosclerosis. To investigate the molecular mechanism by which the TLR5-Nox4 cascade mediates SMC migration, we analyzed the signaling cascade in primary vascular SMCs (VSMCs) from wild-type (WT) or Nox4 KO mice. Stimulation of VSMCs from Nox4 KO mice with flagellin failed to induce $\mathrm{H}_{2} \mathrm{O}_{2}$ production and Rac activation compared with stimulation of VSMCs from WT mice. Moreover, the migration of Nox4-deficient VSMCs was attenuated in response to flagellin in transwell migration and wound healing assays. Finally, we performed partial carotid artery ligation in ApoE KO and Nox4ApoE DKO mice fed a high-fat diet (HFD) with or without recombinant FliC ( $r F l i C$ ) injection. Injection of $r F l i C$ into ApoE KO mice fed a HFD resulted in significantly increased SMC migration into the intimal layer, whereas SMC accumulation was not detected in Nox4ApoE DKO mice. We conclude that activation of the TLR5-Nox4 cascade plays an important role in the formation of neointimal atherosclerotic plaques.
\end{abstract}

\section{Introduction}

It has been well established that vascular inflammation plays an important role in the generation and progression of atherosclerosis ${ }^{1-3}$. Among various types of vascular inflammation, toll-like receptor (TLR)-mediated inflammation in vascular cells is known to be involved in atherosclerosis $^{4-7}$. The expression of TLR1, TLR2, and TLR4 is enhanced in atherosclerotic lesions compared with healthy arteries. TLR isozymes in vascular cells, including endothelial cells (ECs), smooth muscle cells (SMCs), and macrophages, recognize endogenous and exogenous ligands and trigger the expression of downstream proinflammatory molecules, including monocyte chemotactic protein-1 (MCP-1), interleukin-6 (IL-6),

Correspondence: Yun Soo Bae (baeys@ewha.ac.kr)

'Department of Life Science, Ewha Womans University, Seoul, Korea

2Department of Biotechnology, Emory University, Atlanta, GA, USA

These authors contributed equally: Jinoh Kim, Jung-Yeon Yoo interleukin-8 (IL-8), and metalloprotease (MMP), leading to atherosclerosis.

Several lines of evidence indicate that NADPH oxidase (Nox)-induced reactive oxygen species (ROS) generation serves as a second messenger in various cellular events ${ }^{8,9}$. To date, seven Nox isozymes (Nox 1-5 and Duox1-2) have been identified in different tissues and are activated by various agonists, resulting in the regulation of cell growth, differentiation and migration. We previously reported that Nox isozymes become linked with TLRs in ECs, SMCs, and macrophages in response to TLR agonist stimulation. Stimulation of ECs with lipopolysaccharide results in Nox4 activation through direct interaction with the $\mathrm{COOH}$-terminus of TLR4, leading to the production of proinflammatory cytokines and adhesion molecules, including IL-8, MCP-1, and ICAM- ${ }^{10,11}$. In the case of macrophages, TLR activates the Nox2 isozyme in a typical manner. Minimally oxidized low-density lipoprotein (mmLDL) is known to interact with CD14 and activate

\section{(c) The Author(s) 2019}

(c) (i) Open Access This article is licensed under a Creative Commons Attribution 4.0 International License, which permits use, sharing, adaptation, distribution and reproduction cc) in any medium or format, as long as you give appropriate credit to the original author(s) and the source, provide a link to the Creative Commons license, and indicate if changes were made. The images or other third party material in this article are included in the article's Creative Commons license, unless indicated otherwise in a credit line to the material. If material is not included in the article's Creative Commons license and your intended use is not permitted by statutory regulation or exceeds the permitted use, you will need to obtain permission directly from the copyright holder. To view a copy of this license, visit http://creativecommons.org/licenses/by/4.0/. 
the TLR4 complex, inducing the secretion of certain cytokines in macrophages. MmLDL stimulates TLR4mediated activation of Nox2 through a sequential signaling cascade involving Syk, phospholipase $\gamma$ (PLC $\gamma)$, and $\mathrm{PKC}$, resulting in the production of proinflammatory cytokines, including IL-1 $\beta$, IL-6, and RANTES ${ }^{12,13}$. The synthetic triacylated lipoprotein Pam3CSK4, a TLR2 agonist, stimulates $\mathrm{H}_{2} \mathrm{O}_{2}$ generation through interaction of Nox1 with TLR2 in mouse vascular smooth muscle cells (VSMCs) ${ }^{14} \cdot \mathrm{H}_{2} \mathrm{O}_{2}$ generation by the TLR2-Nox1 axis plays a key role in the secretion of the proinflammatory cytokine MIP-2 in VSMCs. Secreted MIP-2 stimulates VSMC migration and vascular remodeling.

Recently, we reported that Nox4 activation by TLR5 stimulates inflammation of ECs and ultimately leads to atherogenesis ${ }^{15}$. Silencing of Nox4 expression by transfection of HAECs with Nox4-specific siRNA attenuated the expression levels of IL-8 and ICAM-1, leading to reduced adhesion and transendothelial migration of monocytes. Moreover, injection of recombinant $\mathrm{FliC}$ $(\mathrm{rFliC})$ into Nox4ApoE DKO mice fed high-fat diets (HFDs) resulted in significantly decreased atherosclerotic plaque sizes compared with injection into ApoE KO mice, suggesting that Nox4 has proatherogenic activity in $\mathrm{rFliC}$ mediated atherosclerosis. Moreover, injection of $\mathrm{rFliC}$ into ApoE KO mice increased the necrotic core size in the sinus valve due to infiltration of monocytes and neutrophils, accumulation of collagen and migration of VSMCs. In this report, we present the function of Nox4 in SMC migration for the generation of vulnerable plaques in response to FliC-TLR5 activation.

\section{Materials and methods Mice}

All animal procedures were approved by the Institutional Animal Care and Use Committees (IACUC) at Ewha Womans University. Nox1 KO mice were purchased from The Jackson Laboratory (Bar Harbor, ME, USA). The generation of Nox4 KO mice has been described in a previous report ${ }^{15}$. Nox4 $\mathrm{KO}$ mice were crossed with ApoE KO mice to generate Nox4ApoE double knockout mice. rFliC purification and endotoxin elimination were performed as described in a previous report ${ }^{15}$. The animal protocols were in compliance with the NIH Guidelines for the Care and Use of Laboratory Animals and have been approved by the IACUC of the Center for Laboratory Animal Sciences, Ewha IndustryUniversity Cooperation Foundation, Ewha Womans University.

\section{Preparation of murine vascular smooth muscle cells}

VSMCs were prepared as described in a previous report ${ }^{14}$. VSMCs were isolated from the thoracic aortas of 8-week-old male wild-type, Nox1 knockout, or Nox4 knockout mice. Each mouse was killed by $\mathrm{CO}_{2}$ inhalation. An incision was made along the midline of the abdomen, the thorax was opened to expose the heart and lungs, and saline containing heparin was slowly perfused into the left ventricle of the heart. The adventitia and connective tissue that surround the aorta were carefully removed with fine forceps. The aorta was cut near the aortic arches, immersed in phosphate-buffered saline (PBS) containing $1 \%$ penicillin and streptomycin (Gibco Laboratories, Gaithersburg, MD, USA) and filled with collagenase type I (Worthington, Lakewood, NJ, USA; $268.32 \mathrm{U} / \mathrm{mL}$, dissolved in serum-deprived Dulbecco's modified Eagle's medium(DMEM)) that had been sterilized by passage through a $0.2 \mu \mathrm{m}$ Millipore membrane. After incubation at $80 \mathrm{rpm}$ for $30 \mathrm{~min}$ at $37^{\circ} \mathrm{C}$, the aorta was chopped with a fine scissor and resuspended with collagenase type I solution. After incubation at $80 \mathrm{rpm}$ for $90 \mathrm{~min}$ at $37^{\circ} \mathrm{C}$, the chopped aorta was centrifuged at $1000 \mathrm{rpm}$ for $3 \mathrm{~min}$, and the pellet was collected and resuspended in $20 \%$ FBSDMEM. The cells were plated onto 35-mm-diameter culture dishes, and the dishes were placed in an incubator and left undisturbed for $\sim 7$ days. The purity of the VSMC preparations was confirmed with an antibody against smooth muscle actin (Supplementary Fig. 1). Three different batches of primary VSMCs were combined at passage 2 , and the combined batch was used in all experiments at passages $4-7$.

\section{Cell culture and antibodies for western blot analysis}

The VSMCs were cultured at $37^{\circ} \mathrm{C}$ in DMEM supplemented with $10 \%(\mathrm{v} / \mathrm{v})$ fetal bovine serum and $1 \%(\mathrm{v} / \mathrm{v})$ antibiotic-antimycotic solution (Gibco Laboratories, Gaithersburg, MD, USA). Cell lysates were subjected to SDSPAGE and transferred to nitrocellulose membranes. The membranes were immunoblotted with anti-phospho-IкB $\alpha$ (Cell Signaling, Danvers, MA, USA, \#2859), anti-IкB $\alpha$ (Cell Signaling, Danvers, MA, USA, \#9242), anti-phosphoJNK (Cell Signaling, Danvers, MA, USA, \#9251), or antiJNK (Cell Signaling, Danvers, MA, USA, \#9252) followed by horseradish peroxidase-conjugated secondary antibodies. The bands were visualized by chemiluminescence (Fujifilm LAS-3000).

\section{Partial carotid ligation surgery}

8-week-old male ApoE KO and Nox4ApoE DKO mice. All procedures were performed according to a protocol approved by the IACUC of Ewha Womans University. Partial ligation of the left carotid artery (LCA) was performed under anesthesia as previously described ${ }^{16}$ to induce low and disturbed flow in the LCA. All mice were fed a chow diet and given water ad libitum until partial ligation. Anesthesia was induced by inhalation of $2-2.5 \%$ $(\mathrm{v} / \mathrm{v})$ isoflurane. Epilated areas were disinfected with betadine, and a ventral midline incision $(4-5 \mathrm{~mm})$ was 
made in the neck. The LCA was exposed by blunt dissection. Three of four caudal branches of the LCA (the left external carotid, internal carotid, and occipital artery) were ligated with 6-0 silk sutures, while the superior thyroid artery was left intact. The incision was then closed with a 5-0 silk suture. The mice were monitored until recovery in a chamber on a heating pad after surgery. Following carotid ligation, disturbed flow in the LCA and laminar flow in the right carotid artery (RCA) was confirmed 1 day post ligation by ultrasonography using a VEVO 2100 system (VisualSonics, Toronto, Canada). The mice were fed Paigen's high-fat diet (Research Diet, New Brunswick, NJ, USA) containing $1.25 \%$ cholesterol, $15 \%$ fat, and $0.5 \%$ cholic acid immediately following partial ligation for 10 days.

\section{Oil Red $O$ staining}

Ten days after the procedure, the carotid arteries were obtained and perfusion-fixed with $10 \%$ formalin. The samples were then embedded in OCT compound and frozen. Five frozen sections (each $6-\mu \mathrm{m}$ thick) $1-2 \mathrm{~mm}$ proximal to the ligation site were obtained from each animal. The areas of the lumen, intima, and media were measured in sections stained with Oil red $\mathrm{O}$ for $10 \mathrm{~min}$ and analyzed with the ImageJ program. The mean value for five sections from each animal was used for analysis.

\section{Immunofluorescence staining}

Frozen sections from carotid arteries were stained with anti-SMA (Santa Cruz Biotechnology, sc-6251, Dallas, TX, USA), anti-Flk-1 (Dako, M0851, Santa Clara, CA, USA), and anti-F4/80 (Abcam, ab6640, Cambridge, England) antibodies.

\section{rFliC purification and elimination of endotoxin}

The preparation of $\mathrm{rFliC}$ has been described in a previous report ${ }^{15}$. Wild-type FliC (AA21-505) and a deletion mutant of FliC (AA119-505) from the Salmonella enteritidis FliC flagellin gene (GenBank Accession No. M84980) were cloned into $\mathrm{pET} 15 \mathrm{~b}$ vectors to generate His epitope-tagged recombinant proteins. The rFliC protein and mutant $\triangle$ FliC protein were eluted from $\mathrm{Ni}^{+}$NTA resin (Qiagen, Hilden, Germany) with elution buffer containing $50 \mathrm{mM}$ phosphate $(\mathrm{pH} 7.4), 20 \mathrm{mM} \mathrm{NaCl}$, $100 \mathrm{mM}$ imidazole and protease inhibitors. The $\mathrm{rFliC}$ and mutant $\triangle$ FliC proteins were passed through an EndoTrap Red endotoxin removal column (Hyglos) to remove potential endotoxin according to the manufacturer's instructions. The endotoxin levels were measured using a Kinetic-QCL limulus amebocyte lysate (LAL) assay (Lonza). The LAL assays showed an endotoxin content of $<0.1 \mathrm{EU} / \mathrm{ml}$ in the purified $\mathrm{rFliC}$ and mutant $\mathrm{rFliC}$ $(\Delta \mathrm{rFliC})$. Standard flagellin from $S$. typhimurium was purchased from InvivoGen. The flagellin used in this experiment contained $0.1-1 \mathrm{EU}$ of endotoxin.

\section{$\mathrm{H}_{2} \mathrm{O}_{2}$ detection}

Measurement of intracellular $\mathrm{H}_{2} \mathrm{O}_{2}$ was performed using DCF-DA and Peroxy Orange-1 (PO-1) as described in a previous report ${ }^{15}$.

\section{Transwell migration assay}

Harvested wild-type and Nox4 knockout SMCs $\left(8 \times 10^{3}\right.$ cells) were replated onto the upper chambers of Transwell filters with $8 \mu \mathrm{m}$ pores (Corning, NY, USA) coated with $10 \mu \mathrm{g} / \mathrm{mL}$ fibronectin, and the chambers were placed in serum-free DMEM with or without $100 \mathrm{ng} / \mathrm{mL}$ ultrapure flagellin (InvivoGen, \#tlrl-epstfla, San Diego, CA, USA). After $16 \mathrm{~h}$, the cells were fixed with $70 \%$ methanol for $5 \mathrm{~min}$. The cells on the underside of each filter were stained with hematoxylin for $5 \mathrm{~min}$ and rinsed with distilled water. The filter was stained with eosin for $3 \mathrm{~min}$ and washed again. Nonmigrating cells on the upper side of the filter were removed with cotton swabs. Images were captured using a Nikon Eclipse 80i microscope. Three independent filters were analyzed for each experiment by counting the number of cells on each filter in five random fields.

\section{Cell proliferation assay (MTT assay)}

Wild-type (WT) and Nox4 KO SMCs $\left(2 \times 10^{3}\right.$ cells/ well) were seeded into 96-well plates and stimulated with flagellin $(100 \mathrm{ng} / \mathrm{mL})$ for $24 \mathrm{~h}$. The cells were incubated for $4 \mathrm{~h}$ with MTT labeling reagent, and then solubilization solution was added (Cell Proliferation Kit I, Roche, Cat. No. 11465007 001, Basel, Switzland). The absorbance was measured at $590 \mathrm{~nm}$.

\section{Wound healing assay}

SMCs $\left(1 \times 10^{5}\right.$ cells $)$ were plated onto 6 -well plates. After the cells reached $90 \%$ confluence, the cells were serum-starved for $4 \mathrm{~h}$ and then treated with mitomycin $(5 \mu \mathrm{g} / \mathrm{mL})$ for $1 \mathrm{~h}$. The cells were scratched with $200 \mu \mathrm{L}$ pipette tips, and the starting point was marked with a marker pen at the bottom of the plate. The cells were washed with PBS three times, the medium was replaced with $0.5 \%$ FBS medium containing flagellin $(100 \mathrm{ng} / \mathrm{mL})$, and the cells were incubated for $24 \mathrm{~h}$. Images were captured using an Axiovert $40 \mathrm{C}$ inverted microscope (Carl Zeiss, Oberkochen, Germany) equipped with a PowerShot A640 digital camera (Canon, Tokyo, Japan).

\section{Single-cell tracking through confocal microscopy ${ }^{17}$}

SMCs were prepared for live-cell imaging prior to being placed in an incubation chamber (Chamlide TC; Live Cell Instrument, Seoul, Korea) kept at $37^{\circ} \mathrm{C}$ and $5 \% \mathrm{CO}_{2}$. Briefly, the cells were cultured in a 12-well dish containing 
coverslips $\quad$ (diameter $=12 \mathrm{~mm}, \quad$ Marienfeld, Germany) coated with $0.01 \%$ poly-L-lysine (Sigma-Aldrich, St. Louis, MO, USA). The cells were stained with $5 \mu \mathrm{M}$ DRAQ5 (1,5-bis \{[2-(di-methylamino) ethyl] amino\}-4,8-dihydroxyanthracene-9,10-dione, ab108410, Abcam, Cambridge, UK), a cell permeable far-red fluorescent DNA dye, to track single-cell migration. At the same time, the cells were stimulated with or without flagellin $(100 \mathrm{ng} / \mathrm{mL})$. Confocal images were obtained with a Nikon A1R confocal microscope for $4 \mathrm{~h}$ using a $60 \times$ Plan Apochromat VC objective (NA 1.40) under illumination with a $633 \mathrm{~nm}$ laser. All images were processed, and quantification for single-cell tracking was performed using Nikon NIS Element $\mathrm{C}$ software (version 3.10).

\section{Quantitative real-time PCR analysis}

Quantitative real-time PCR was used to analyze the expression levels of Nox isozymes using a TaqMan gene expression assay (Applied Biosystems, Foster City, CA, USA). The experiments were performed with KAPA PROBE FAST Universal $2 \times$ qPCR Master Mix (KAPA Biosystems, Basel, Switzerland). Glyceraldehyde-3phosphate dehydrogenase (GAPDH) served as a housekeeping gene and internal control. The expression levels of other genes were quantified with a KAPA SYBR ${ }^{\circ}$ FAST qPCR Kit (KAPA Biosystems, Basel, Switzerland) using the following specific primers: mouse ICAM-1, 5'-A GGTGGTTCTTCTGAGCGGC-3' and 5'-AAACAGGAA CTTTCCCGCCA-3'; mouse VCAM-1, 5'-TCTTGGGA GCCTCAACGGTA-3' and 5'-CAAGTGAGGGCCATGG AGTC-3'; mouse MCP-1, 5'-GAAGGAATGGGTCCAG ACAT-3' and 5'-ACGGGTCAACTTCACATTCA-3'; mouse RANTES, 5'- TGCCCACGTCAAGGAGTAT TTC-3' and 5'-AACCCACTTCTT CTCTGGGTTG-3'; mouse IL-1 $\beta$, 5'-CAACCAACAAGTGATATTCTCCA TG-3' and 5'-GATCCACACTCTCCAGCTGCA-3'; mou se TNF- $\alpha, \quad 5$-CACGTCGTAGCAAACCACCAAGTG GA-3' and 5'-TGGGAGTAGACAAGGTACAACCC-3'; mouse IL-6, 5'-TCCGGAGAGGAGACTTCACA-3' and 5'-TGCAAGTGCATCATCGTTGT-3'; and mouse 18S, 5'-AGGAATTGACGGAAGGGCACCA-3' and 5'-GTG CAGCCCCGGACATCTAAG-3'. The $18 \mathrm{~S}$ ribosomal RNA gene served as a housekeeping control. The fold changes in target gene expression were normalized by analyzing the cycle number for each gene with the $2^{-\Delta \Delta \mathrm{Ct}}$ method.

\section{Determination of IL- 6 protein levels}

SMCs $\left(1 \times 10^{5}\right.$ cells $)$ from WT or Nox 4 KO mice were incubated with or without flagellin $(100 \mathrm{ng} / \mathrm{mL})$ for $12 \mathrm{~h}$, and then the medium was collected. The IL-6 protein levels were determined with an ELISA kit according to the manufacturer's instructions (R\&D Systems, Minneapolis, MN, USA, M6000B).

\section{Rac activity assay}

Glutathione Sepharose 4B-conjugated GST-PAK-RBD was prepared as previously described for a Rac activity assay $^{18}$. The bead-conjugated GST-PAK-RBD was incubated for $1 \mathrm{~h}$ at $4{ }^{\circ} \mathrm{C}$ in lysis buffer with lysates of wild-type and Nox4 knockout SMCs. The beads were then separated by centrifugation, washed three times and subjected to immunoblot analysis with monoclonal antibodies against Rac1 (Millipore, Billerica, MA, USA).

\section{RhoA activity assay}

RhoA activity was measured using a RhoA pulldown assay Kit (Cytoskeleton, Denver, CO, USA) according to the manufacturer's instructions. Briefly, WT and Nox4 KO SMCs were serum-starved for $16 \mathrm{~h}$ and stimulated with flagellin $(100 \mathrm{ng} / \mathrm{mL})$ for $1 \mathrm{~h}$. The cells were lysed on ice in lysis buffer and then centrifuged at $12,000 \times g$ for $5 \mathrm{~min}$. The cell debris was removed, and the supernatants were incubated with rhotekin-RBD beads for $1 \mathrm{~h}$ at $4{ }^{\circ} \mathrm{C}$ on a rotator. The beads were washed, and the immunoprecipitated complex was resuspended in $2 \times$ SDS sample buffer and subjected to $12 \%$ SDS-PAGE followed by western blotting.

\section{Statistical analysis}

The data are given as the mean $\pm \mathrm{SD}$ or the mean \pm SEM. Pairwise comparisons were performed using Student's $t$-tests. Multiple comparisons of means were calculated using one-way analysis of variance (ANOVA) (GraphPad Software, La Jolla, CA, USA). Differences between groups were considered significant at $P$ values $<$ 0.05 .

\section{Results}

Nox4 is required for flagellin-induced $\mathrm{H}_{2} \mathrm{O}_{2}$ generation in smooth muscle cells

We previously reported that the flagellin-TLR5-Nox4 axis mediates inflammation processes in aortic ECs, leading to the formation of initial atherosclerotic plaques $^{15}$. During the progression of atherosclerosis, atherosclerotic lesions became vulnerable plaques that contain large necrotic cores and exhibit vascular remodeling, including SMC migration and extracellular matrix (ECM) accumulation. To evaluate the function of Nox4 in the formation of atherosclerotic plaques, ROS generation was examined in primary mouse VSMCs (Supplementary Fig. S1) in response to flagellin by measuring the fluorescence of 2',7'-DCF-DA by confocal microscopy. Stimulation of WT mouse SMCs with flagellin significantly increased ROS generation (Fig. 1a). Flagellin-induced ROS generation was inhibited by pretreatment with the Nox inhibitors VAS2870 and GKT137831 (Fig. 1b). To validate which ROS is involved in flagellin stimulation, we treated cells with cell-permeable polyethylene glycol 


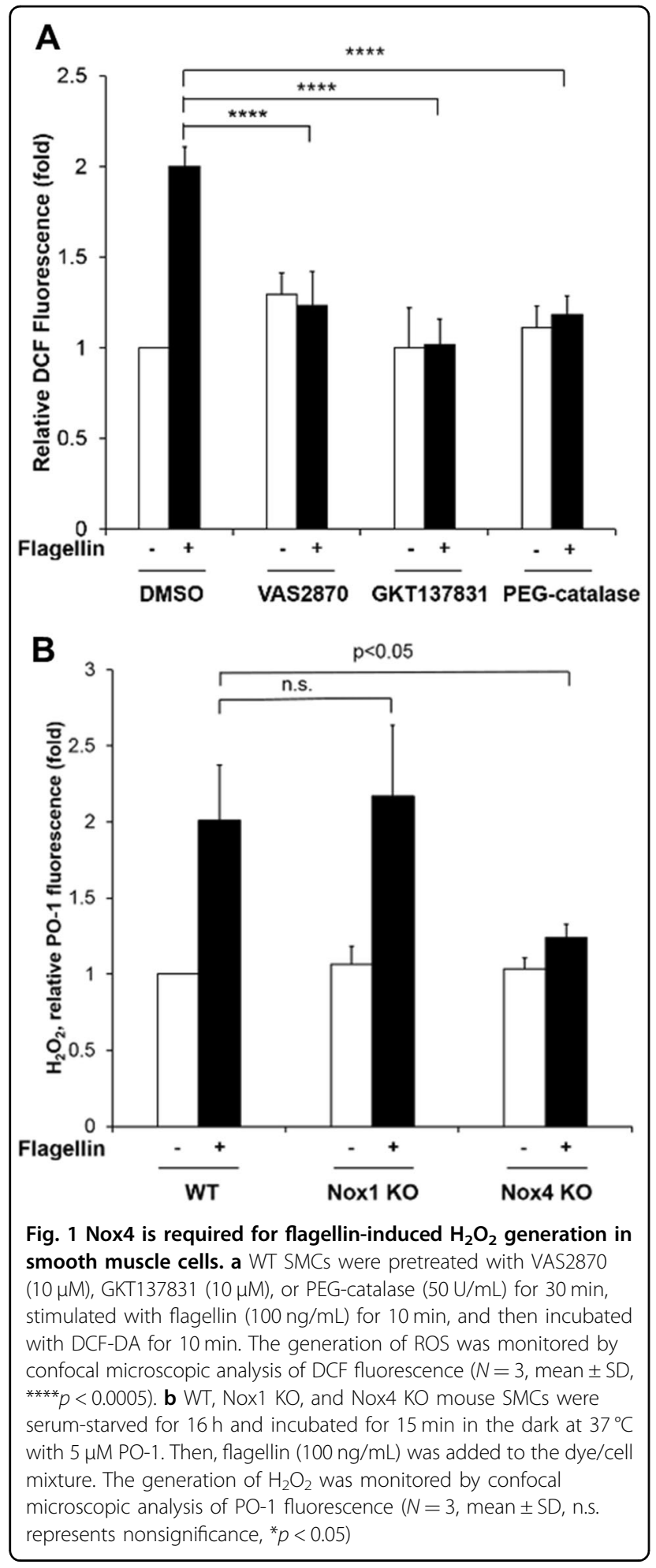

(PEG)-conjugated catalase. PEG-conjugated catalase completely suppressed ROS generation, indicating that the predominant flagellin-dependent ROS is $\mathrm{H}_{2} \mathrm{O}_{2}$ (Fig. 1a). We wondered whether the Nox isozyme is responsible for $\mathrm{H}_{2} \mathrm{O}_{2}$ generation in response to flagellin.
We first measured the levels of Nox isozyme expression in primary VSMCs. Nox4 was the predominant isozyme, and the Nox1 isozyme was the minor form in primary VSMCs (Supplementary Fig. S2). We prepared primary VSMCs from the aortas of WT, Nox4 KO and Nox1 KO mice and detected $\mathrm{H}_{2} \mathrm{O}_{2}$ generation by using a Peroxy Orange- 1 (PO-1) dye, which is sensitive specifically to $\mathrm{H}_{2} \mathrm{O}_{2}$. Stimulation of WT and Nox1 KO VSMCs with flagellin resulted in significantly increased $\mathrm{H}_{2} \mathrm{O}_{2}$ generation, whereas Nox4 KO VSMCs failed to generate $\mathrm{H}_{2} \mathrm{O}_{2}$ in response to flagellin (Fig. 1b).

\section{Flagellin-dependent NF-kB activation requires Nox4 activity in SMCs}

In a previous report, we showed that the TLR5-Nox4$\mathrm{H}_{2} \mathrm{O}_{2}$ cascade induces the activation of NF- $\mathrm{kB}$ as a hallmark of inflammatory signaling in the endothelium ${ }^{15}$. We next validated whether the TLR5-Nox4- $\mathrm{H}_{2} \mathrm{O}_{2}$ axis regulates NF-kB activation in VSMCs. Stimulation of SMCs with flagellin failed to induce nuclear localization of RelA/ p65, a subunit of NF-kB, in Nox4 KO SMCs compared with WT SMCs, indicating that the TLR5-Nox4 cascade stimulates NF-kB signaling (Fig. 2a, b). To confirm the flagellin-dependent NF-kB activation in VSMCs, we measured I $\mathrm{kB}$ phosphorylation and degradation in response to flagellin. Stimulation of WT SMCs with flagellin resulted in increased IkB $\alpha$ phosphorylation and degradation (Fig. 2c). Moreover, the ratio of phosphorylated $I k B \alpha$ to $I k B \alpha$ was significantly increased in WT SMCs but not in Nox4 SMCs (Fig. 2c). However, Nox4 KO SMCs failed to phosphorylate and degrade $\mathrm{IkB}$ in response to flagellin (Fig. 2c). These results show that flagellin stimulates NF-kB activation through IkB degradation. These results indicated that Nox4 is an essential molecule in flagellin-dependent NF-kB activation in SMCs.

\section{Function of the TLR5-Nox4-NF-kB axis in the flagellin-} induced expression of proinflammatory molecules in SMCs

We next explored whether the TLR5-Nox4 axis regulates the production of proinflammatory cytokines in SMCs. The differential expression of proinflammatory cytokines between WT and Nox4 KO SMCs was determined. The expression of the chemoattractants RANTES and IL-6 and the adhesion molecule ICAM-1 was downregulated in Nox4 KO SMCs in response to flagellin (Fig. 3a, c, and f). However, the expression profiles of MCP-1, IL- $1 \beta$, and TNF- $\alpha$ were not changed in either group of cells in response to flagellin (Fig. 3b, d, and e). Moreover, we found that the protein levels of IL-6 were attenuated in flagellin-treated Nox4 KO SMCs compared with WT SMCs (Fig. 3g). Many reports have suggested that the flagellin-TLR5-Nox4-NFkB axis stimulates the expression of proinflammatory cytokines. We attempted 


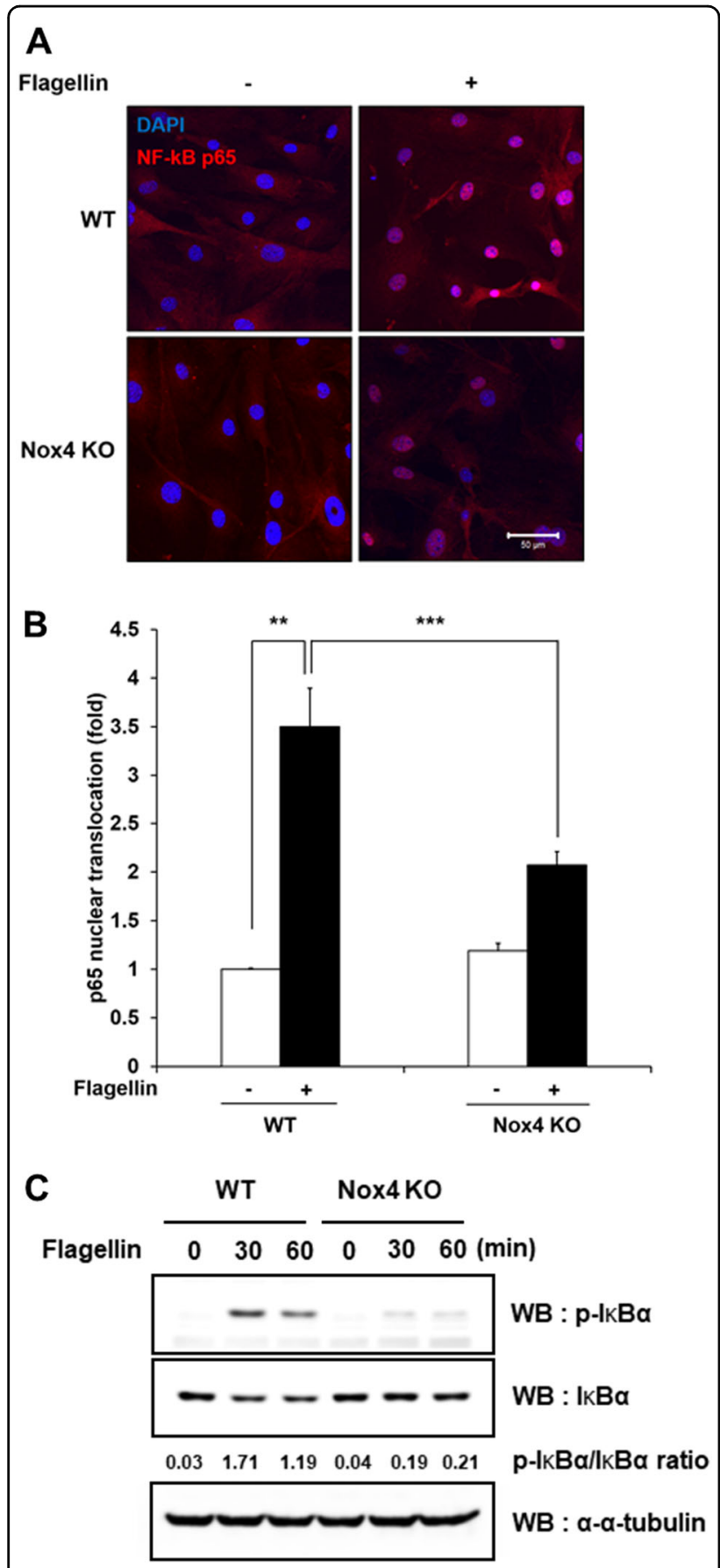

Fig. 2 Nox4 is required for flagellin-induced NF-kB activation in smooth muscle cells. a WT and Nox4 KO SMCs were stimulated with flagellin $(100 \mathrm{ng} / \mathrm{mL})$ for $1 \mathrm{~h}$ and stained with a p65 antibody (red) and DAPI (blue). A representative image is shown. Scale bar $=50 \mu \mathrm{m}$. $\mathbf{b}$ Nuclear-translocated p65 was quantified using the ImageJ program $\left(N=3\right.$, mean $\left.\pm S D,{ }^{* *} p<0.01,{ }^{* * *} p<0.001\right)$. c Immunoblotting of phosphorylated $\mathrm{IkBa}$ and $\mathrm{IkBa}$

to determine whether this signaling axis regulates IL-6. Pretreatment of SMCs with Bay 11-7082, an NF-kB inhibitor, resulted in suppressed IL-6 expression, indicating that NF-kB activation by the TLR5-Nox4 axis leads to the expression of proinflammatory cytokines, including IL-6 (Fig. 3h).

\section{The TLR5-Nox4 cascade regulates flagellin-induced smooth} muscle cell migration

We then investigated whether a TLR5-Nox4- $\mathrm{H}_{2} \mathrm{O}_{2}$ cascade regulates SMC migration. Transwell migration assays with WT and Nox4 KO SMCs in the absence or presence of flagellin were performed. Migration of WT SMCs was enhanced in the presence of flagellin, whereas Nox4 KO SMCs failed to migrate in response to flagellin (Fig. 4a, b). It has been reported that phenotypic changes in SMCs contribute to cell migration as well as proliferation ${ }^{19}$. We next investigated whether Nox4 regulates the proliferation of SMCs. Stimulation of VSMCs from WT mice with flagellin resulted in significant increases in cell proliferation (Supplementary Fig. S3). However, flagellin failed to induce cell proliferation in VSMCs from Nox4 KO mice (Supplementary Fig. S3). These results are consistent with previous results ${ }^{20-22}$. To eliminate the effect of proliferation on VSMC migration, we pretreated cells with mitomycin $\mathrm{C}(5 \mu \mathrm{g} / \mathrm{mL})$ for $1 \mathrm{~h}$ before flagellin stimulation in a migration assay. Mitomycin $\mathrm{C}$ is a wellknown potent DNA crosslinker that prevents cell proliferation. To confirm the effect of Nox4 on SMC migration, we performed a wound healing assay with cells pretreated with mitomycin C. Flagellin stimulated WT SMC migration into the wound area (Fig. 4c, d). However, Nox4 KO SMCs did not efficiently migrate into the wound area (Fig. 4c, d). To validate the role of Nox4 in SMC migration in response to flagellin, we attempted live cell imaging with both groups of SMCs in the presence of flagellin. Live single-cell tracking analysis showed that the migration path length of Nox4 KO SMCs was reduced by $35 \%$ compared with that of WT SMCs in response to flagellin (Fig. 4e and Supplementary Fig. S4). These results demonstrated that Nox4 plays an important role in SMC migration.

\section{Flagellin-induced SMC migration requires RhoA and Rac1 activation through JNK activation}

We investigated the molecular mechanism by which the TLR5-Nox4 cascade regulates SMC migration. Rho family GTPases, such as RhoA and Rac1, are well-known molecules in cell migration. We investigated the activation of RhoA and Rac1 in SMCs in response to flagellin. Flagellin greatly enhanced the activation of RhoA and Rac1 in WT SMCs, whereas neither GTPase was activated in Nox4 KO SMCs in response to flagellin (Fig. 5a, b). Several lines of evidence suggest that the TLR5-mediated signaling cascade is involved in JNK activation ${ }^{23-25}$. We next investigated flagellin-mediated JNK activation in Nox4-deficient SMCs. Flagellin stimulated JNK activation 


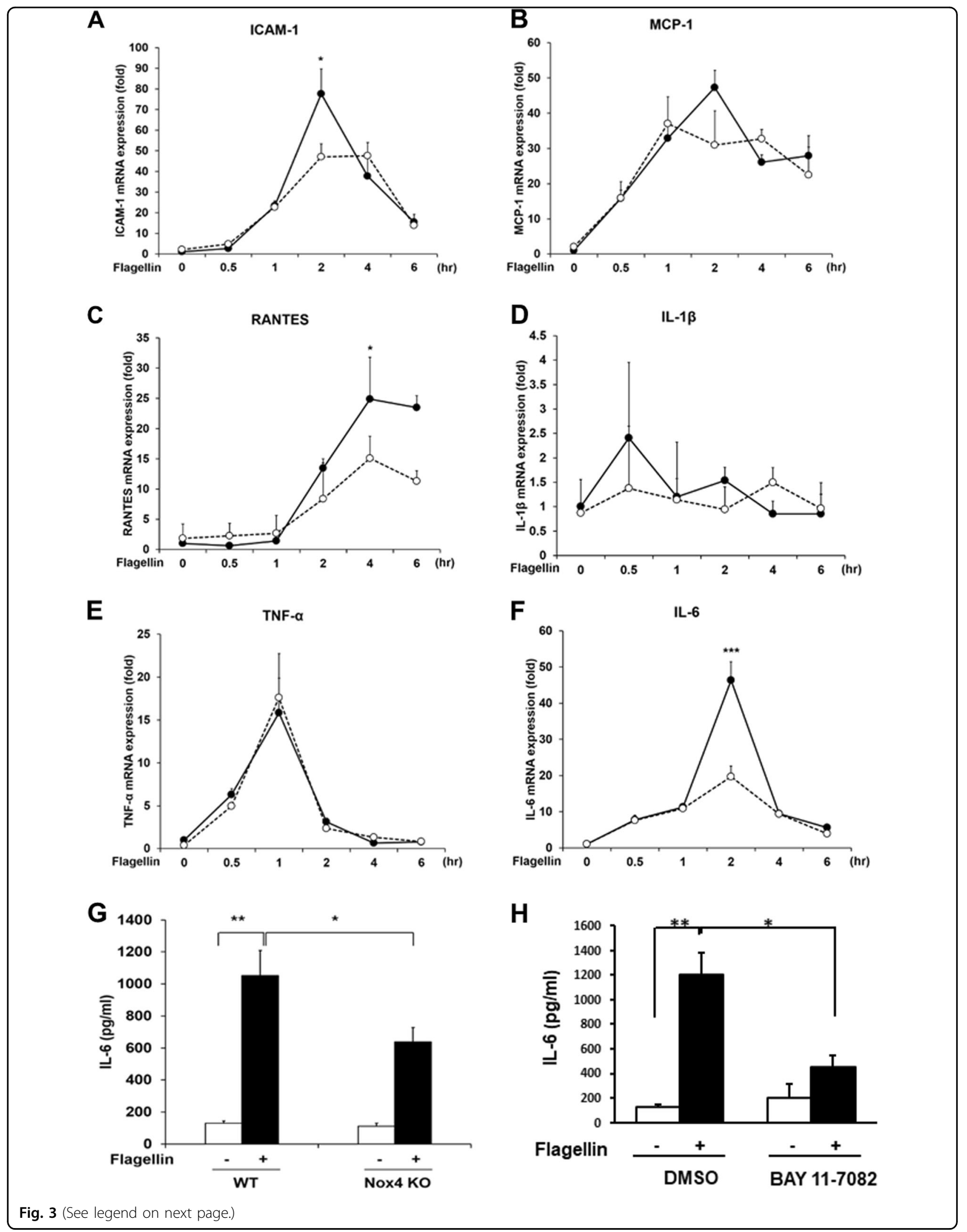


(see figure on previous page)

Fig. 3 Nox4 is required for flagellin-induced inflammation in smooth muscle cells. The results are presented as fold increases in mRNA levels in flagellin-stimulated cells compared with unstimulated cells (black circles: WT SMCs, white circles: Nox4 KO SMCs) (a-g). a Quantification of ICAM-1 mRNA expression in VSMCs $\left(N=3\right.$, mean $\pm S D$, compared with the Nox4 KO SMC group, $\left.{ }^{*} p<0.05\right)$. b Quantification of MCP- 1 mRNA expression. $(N=3$, mean $\pm S D)$. c Quantification of RANTES mRNA expression $\left(N=3\right.$, mean $\pm S D$, $\left.{ }^{*} p<0.05\right)$. d Quantification of IL-1 $\beta$ mRNA expression $(N=3$, mean $\pm \mathrm{SD})$. e Quantification of TNF-a mRNA expression $(N=3$, mean $\pm \mathrm{SD})$. $\mathbf{f}$ Quantification of IL-6 mRNA expression $\left(N=3\right.$, mean $\pm S D,{ }^{* * *} p<$ 0.001). $\mathbf{g}$ WT and Nox4 KO SMCs were stimulated with flagellin $(100 \mathrm{ng} / \mathrm{mL})$ for $12 \mathrm{~h}$. IL-6 protein secretion was analyzed by ELISA ( $N=3$, mean \pm SD, $\left.{ }^{*} p<0.05,{ }^{* *} p<0.01\right)$. $\mathbf{h}$ Effect of an NF-kB inhibitor (BAY11-7082) on IL-6 expression in WT SMCS

in WT SMCs but failed to activate it in Nox4 KO SMCs (Fig. 5c). To validate the role of JNK in cell migration, SP600125, a JNK inhibitor, was applied, and flagellinmediated cell migration was assessed. Treatment of SMCs with SP600125 suppressed cell migration, indicating that JNK activation is an essential event during flagellininduced SMC migration (Fig. 5d).

\section{Reduced atherosclerotic lesion formation and SMC migration in Nox4 KO mice after partial carotid artery ligation}

To determine the effect of Nox4 on neointimal formation in arteries, we established a carotid artery injury model through partial carotid artery ligation in Nox4 KO mice. High-resolution ultrasound (VEVO 2100 highresolution in vivo microimaging ultrasound system, VisualSonics) provided the flow velocity profiles of the mouse carotid arteries. Partial ligation of the left common carotid artery (LCA) induced flow reversal (as indicated by the arrows in Supplementary Fig. S5) during diastole, while flow in the right common carotid artery (RCA) remained unchanged after ligation of the LCA. We found that partial ligation of the LCA in WT mice induced atherosclerotic lesions and that injection of $\mathrm{rFliC}$ with partial ligation of the LCA accelerated atherosclerosis (Fig. 6a, b). However, the atherosclerotic lesions associated with partial ligation of the LCA or with injection of rFliC combined with partial ligation of the LCA were significantly suppressed in Nox4 KO mice. These results indicated that deficiency of Nox4 significantly inhibits the development of atherosclerosis induced by partial ligation and $\mathrm{rFliC}$ injection. To verify the migration of SMCs and the infiltration of macrophages in this animal model, we quantified the SMCs and macrophages in the intima in mice subjected to partial ligation of the LCA. SMC migration (Fig. 6c) and macrophage infiltration (Supplementary Fig. S6) were significantly increased in ApoE KO mice subjected to $\mathrm{rFliC}$ injection and partial ligation of the LCA, whereas migration and infiltration were not detected in Nox4ApoE DKO mice. These results strongly indicate that the flagellin-TLR5-Nox4 axis is essential for SMC migration and macrophage infiltration in the development of atherosclerosis.

\section{Discussion}

The formation of initial atherosclerotic plaques is induced by monocyte/macrophage interaction with the endothelium, monocyte/macrophage infiltration, and foam cell formation, which leads to neointimal hyperplasia. Next, lesion progression includes SMC migration into the neointimal area ${ }^{1-3}$. The pathological intimal thickening in mid-stage atherosclerosis is tightly associated with uptake of modified lipoproteins by VSMCs, apoptosis of VSMCs, and accumulation of extracellular protective fibrous caps overlying the thrombotic lipid cores of advanced lesions ${ }^{26,27}$. We previously revealed the role of the TLR5-Nox4 axis in atherogenesis in response to flagellin stimulation ${ }^{15}$. We demonstrated that the TLR5Nox4 cascade, in particular, induces the proinflammatory stage in ECs, leading to the formation of atherosclerotic plaques. In this study, we found that Nox4 deficiency attenuated the expression of proinflammatory cytokines in SMCs and the migration of SMCs in response to flagellin stimulation, indicating that the flagellin-TLR5-Nox4 signaling cascade is an important mediator in the formation of intimal hyperplasia in atherosclerosis (Fig. 7).

When different types of cells are stimulated by specific agonists, each cell type shows a distinct and specific response. This likely involves specific responses by cell surface receptors as well as cell type-specific communication between downstream signaling proteins. Many studies have reported that flagellin stimulates proinflammatory cytokine production in various cell types ${ }^{28-31}$. We have previously shown that the flagellin-TLR5-Nox4 axis stimulates IL-8 expression in ECs. However, we present here that the flagellin-Nox4 cascade induces IL-6 expression in SMCs. Flagellin-mediated IL-1 $\beta$ or TNF- $\alpha$ production in gastric mucosal cells and hepatocytes is connected with cellular transformation ${ }^{20-22}$. Based on previous reports and our results, we can assume that flagellin stimulation in vascular cells such as ECs and SMCs regulates IL-8 or IL-6 expression, while in mucosal epithelial cells, the agonist induces IL- $1 \beta$ or TNF- $\alpha$ production. NF-kB activation plays an important role in the production of proinflammatory cytokines, including IL$1 \beta$, TNF- $\alpha$, IL-8, and IL-6. Flagellin activates NF-kB as well as MAPK and PKA ${ }^{30,32-34}$. Various cytosolic kinases 

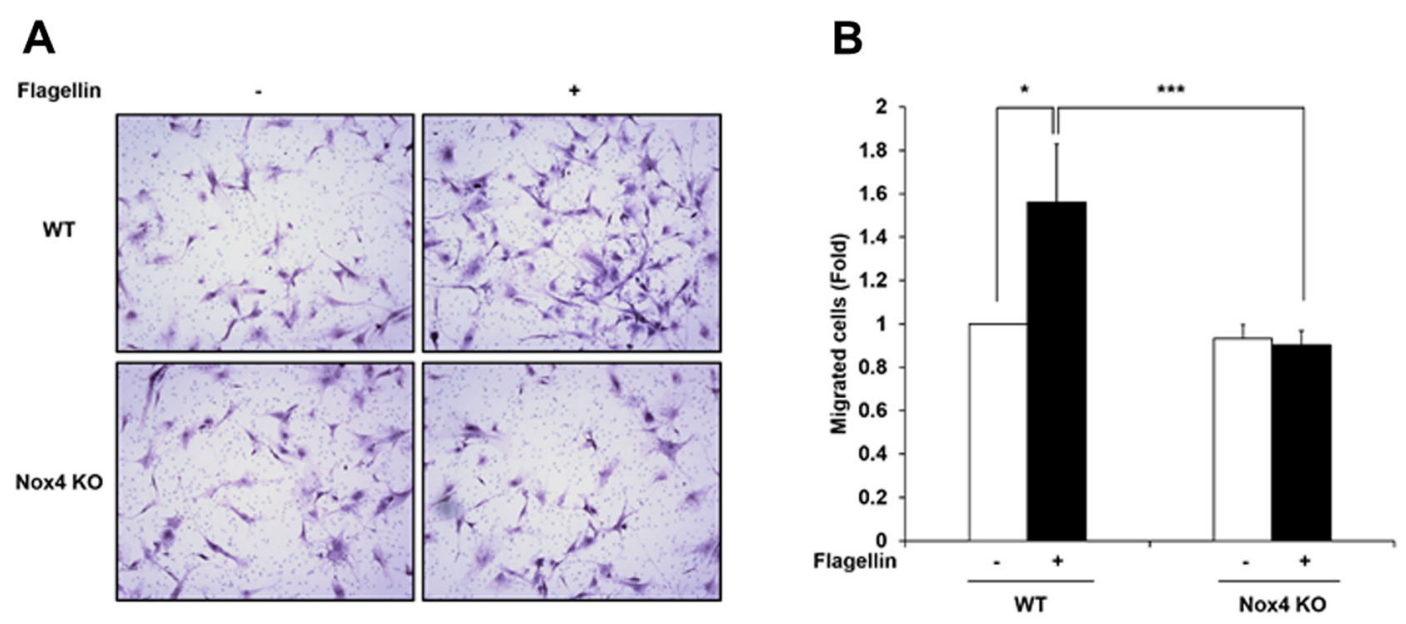

C
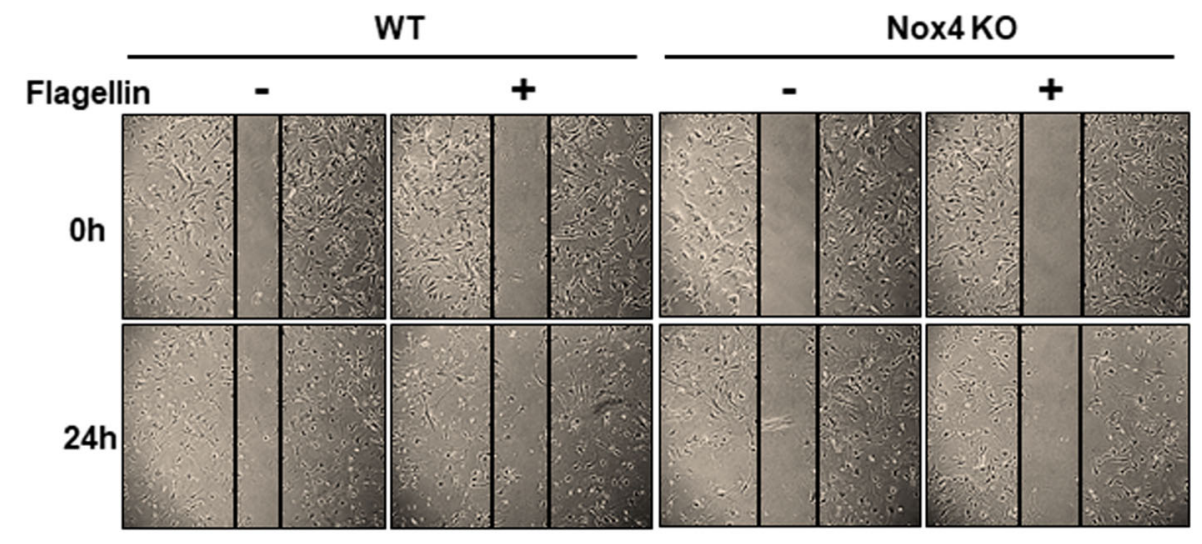

D

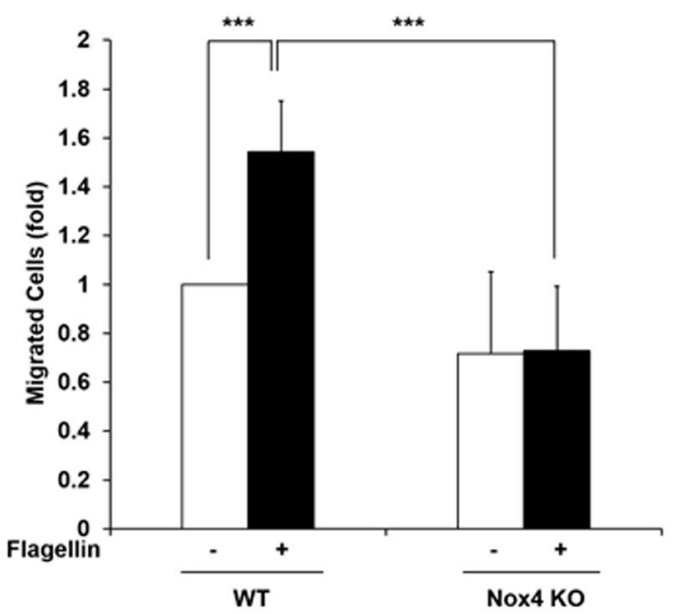

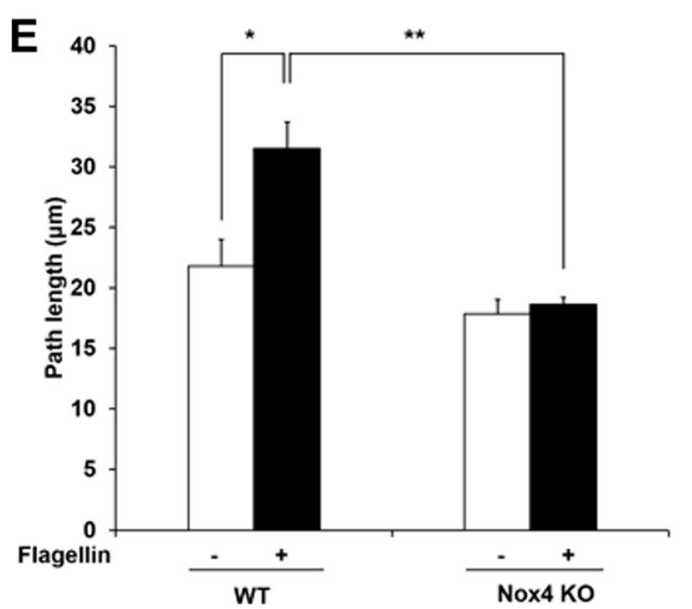

Fig. 4 Nox4 regulates the flagellin-induced migration of smooth muscle cells. a Transwell migration assay. WT and Nox4 KO SMCs were seeded into the upper chamber, and stimulating medium containing flagellin $(100 \mathrm{ng} / \mathrm{mL})$ was added to the lower chamber. After $16 \mathrm{~h}$, the migrated cells were stained with hematoxylin/eosin and counted. Representative images are shown for each group. $\mathbf{b}$ Quantification of the transwell migration assay results $\left(N=5\right.$, mean $\left.\pm S D,{ }^{*} p<0.05,{ }^{* * *} p<0.001\right)$. c Wound healing assay. After WT and Nox4 KO SMCs (initial cell number: $1 \times 10^{5}$ cells) reached $90 \%$ confluence, the cells were serum-starved for $4 \mathrm{~h}$ and then pretreated with mitomycin C (5 $\mathrm{\mu g} / \mathrm{mL})$ for $1 \mathrm{~h}$. The SMCs were subjected to injury by scratching and then incubated with or without flagellin $(100 \mathrm{ng} / \mathrm{mL})$ for $24 \mathrm{~h}$. $\mathbf{d}$ The migrated cells in the wound healing assay were quantified $\left(N=5\right.$, mean $\left.\pm S D,{ }^{* *} p<0.001\right)$. e The path length of the migrating cells after $4 \mathrm{~h}$ is presented as the mean $\pm S D$ from three independent experiments $\left(n=9\right.$ cells). ${ }^{* *} p<0.01$ (Student's t- test) 


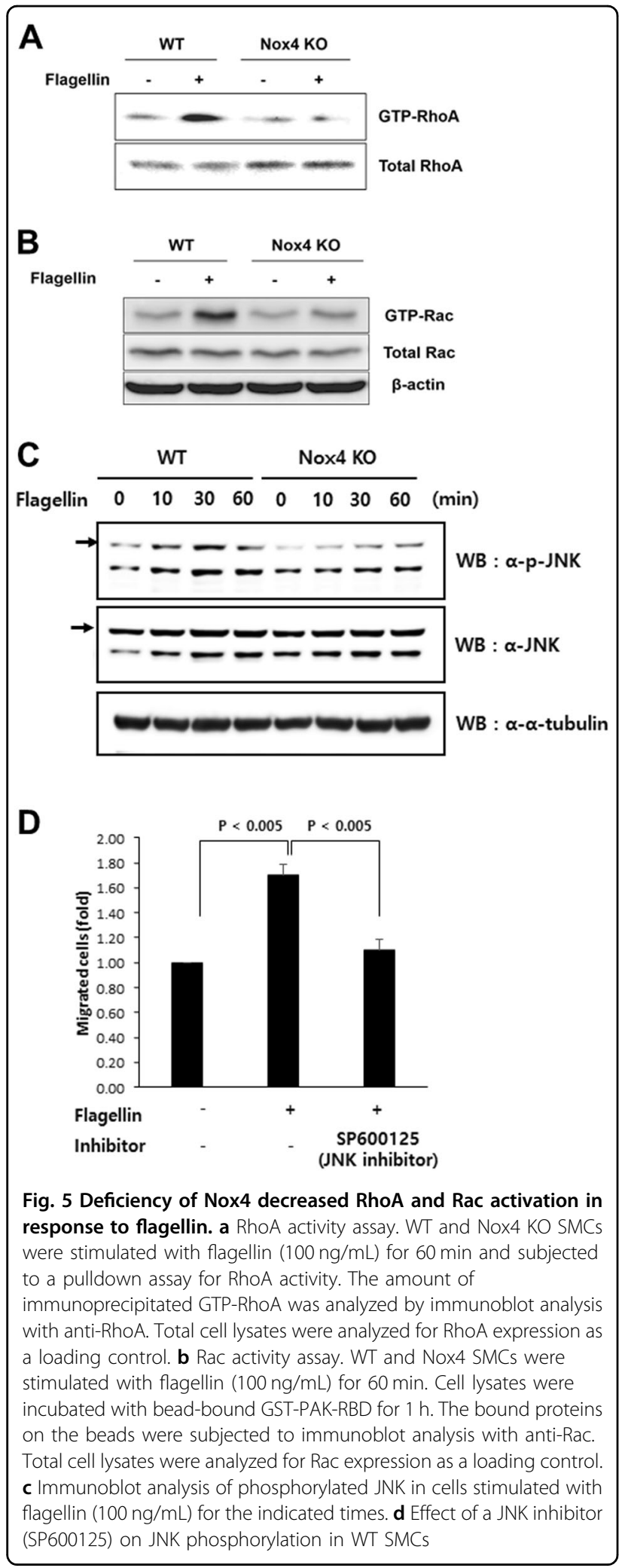

and their signaling cascades communicate with each other, leading to downstream events. For example, MAPK stimulates NF-kB transcriptional activity, whereas PKA suppresses $\mathrm{it}^{30,34}$. We have demonstrated here that flagellin stimulates IL-6 expression in SMCs. In vascular cells, the integration of various activation events induced by flagellin apparently leads to the induction of IL-6 but not of IL- $1 \beta$ or TNF- $\alpha$. However, the molecular mechanism by which flagellin regulates the differential expression of proinflammatory cytokines in different cell types remains to be elucidated.

Vascular inflammation is known to be mediated by innate immunity molecules, including TLR2 and TLR4, resulting in atherogenesis ${ }^{5,35}$. Inflammation due to innate immunity induces dysfunction of vascular ECs and stimulates the production of proinflammatory cytokines, thereby triggering vascular remodeling, including SMC migration (Fig. 6). Among proinflammatory cytokines, interleukin 6 (IL-6) is a potent regulator coordinating cellular functions to maintain vessel walls ${ }^{36}$. Within the vessel wall, inflammation of vascular SMCs can significantly contribute to vascular remodeling. IL-6 regulates trans-signaling, including SMCleukocyte interactions. Dysregulated cellular functions resulting from IL-6 production induce SMC migration and deposition of ECM, leading to the development of neointimal hyperplasia in atherosclerosis. Moreover, it has been reported that the TLR4-MyD88 pathway stimulates SMC migration through CREB-dependent IL-6 production $^{23,37}$. In this report, we have shown that the flagellin-TLR5-Nox4 cascade stimulates the expression of proinflammatory cytokines such as RANTES, IL-6 and the adhesion molecule ICAM-1. The chemoattractant RANTES and the adhesion molecule ICAM-1 may be involved in leukocyte recruitment into the intima. Within local inflammation sites, IL-6 serves as a potent component for mediating SMC-leukocyte interactions. Moreover, instability of atherosclerotic plaques occurs predominantly at the fibrous caps of plaques with accumulated inflammatory cells, including macrophages, $\mathrm{T}$ lymphocytes, and VSMCs ${ }^{38,39}$. The accumulated inflammatory cells stimulate the release of inflammatory cytokines, such as IL-6, which is known to be involved in the stimulation of matrix-degrading enzymes. The degradation of the framework by matrix-degrading enzymes triggers instability in the plaque caps, leading to plaque rupture.

Several lines of evidence suggest that flagellin is involved in the production of proinflammatory cytokines, including MIP-2 (CXCL2), RANTES, and IL-6, through the regulation of transcriptional factors, such as AP-1 and NF-kB. RANTES and IL-6 play important roles in the recruitment of vascular SMCa into the intima of the vascular wall to form the fibrous caps of atherosclerotic lesions. Recently, several clinical studies on atherosclerosis have suggested that IL-6 seems to be a potential marker for atherosclerosis. IL-6 levels are associated with future vascular risk $^{38,40}$. A meta-analysis performed by the Emerging Risk Factors Collaboration ultimately demonstrated that an enhanced level of IL- 6 is associated with a $25 \%$ increase in 


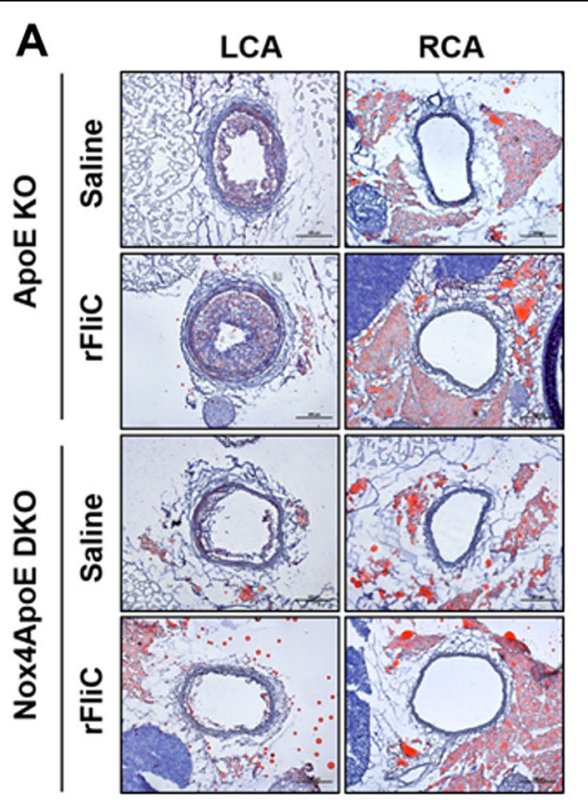

B

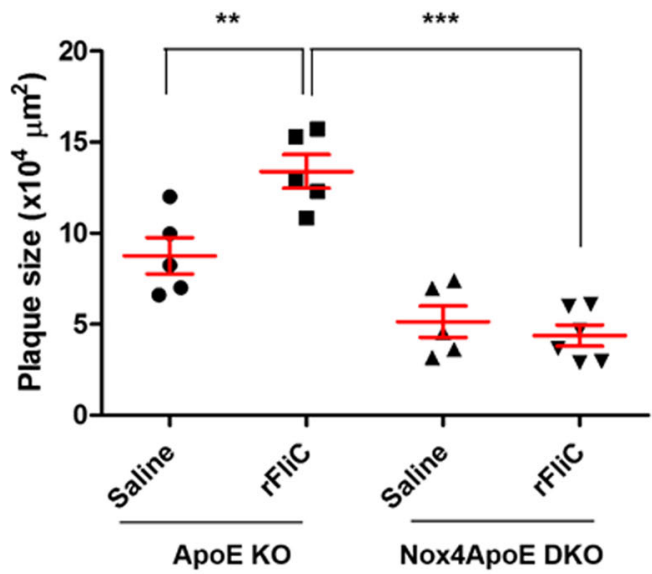

C

DAPI

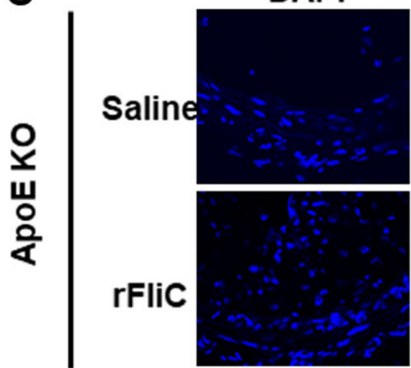

SMA

Flk-1
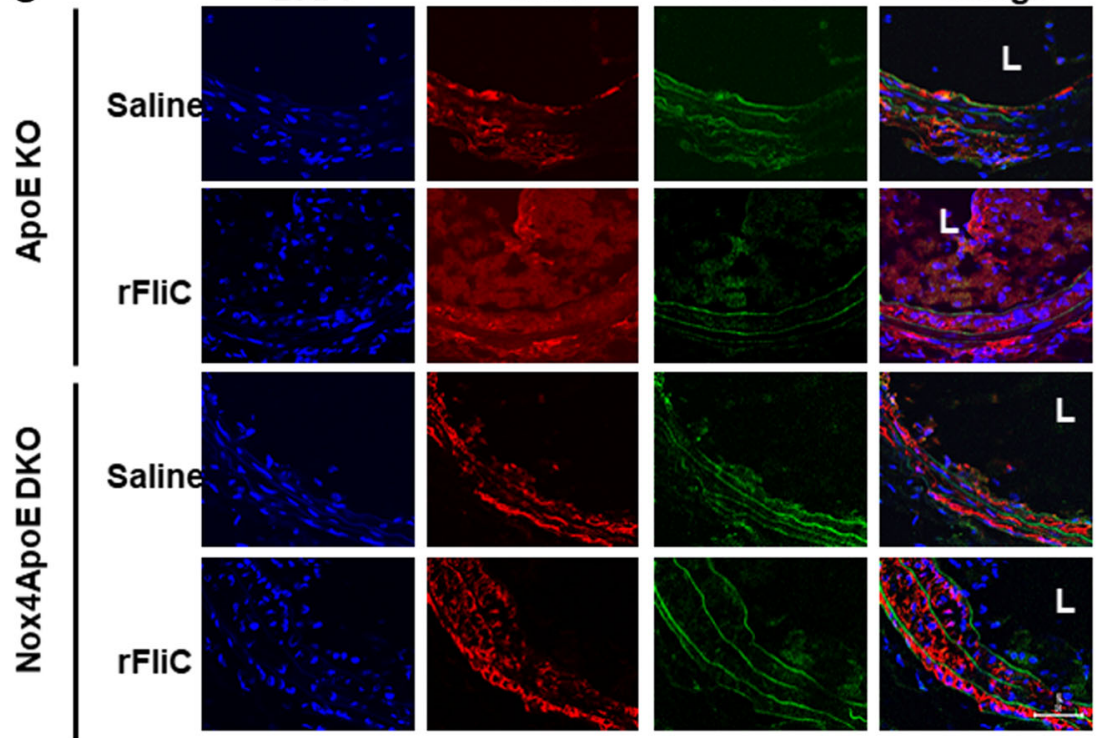

Fig. 6 Nox4 regulates flagellin-induced plaque formation and SMC migration in a partial carotid artery ligation model. a Oil red O staining of the left carotid artery (LCA) and right carotid artery (RCA) 10 days after partial ligation surgery ( $1 \mathrm{~mm}$ from the ligation site, scale bar $=200 \mu \mathrm{m}$ ). b Quantification of plaque sizes using ImageJ ( $N=5$, mean \pm SEM, ${ }^{* *} p<0.01$, ${ }^{* * *} p<0.001$ ). c Immunofluorescence for SMA (red) and Flk-1 (green). The color-merged images are shown in the right panels. Scale bar $=50 \mu \mathrm{m}$

the risk of future vascular events. IL- 6 levels have been shown to correlate with endothelial dysfunction, arterial stiffness, and the extent of subclinical atherosclerosis linked to plaque initiation and destabilization.

In conclusion, we found that atherosclerotic lesion area, necrotic core size, and SMC content were suppressed in Nox4ApoE DKO mice, suggesting a role for Nox4 in neointimal SMC thickening in atherosclerotic plaques. We showed that the TLR4-Nox4-NF-kB signaling cascade stimulates the expression of proinflammatory cytokines and that the TLR4-Nox4-Rac-JNK axis regulates the migration of SMCs. Nox4ApoE DKO mice fed a HFD and injected with $\mathrm{rFliC}$ failed to exhibit recruitment of SMCs into the intimal area. Taken together, these results demonstrate that TLR5mediated Nox4 activation regulates the migration of SMCs, leading to neointimal plaque formation in atherosclerosis. 


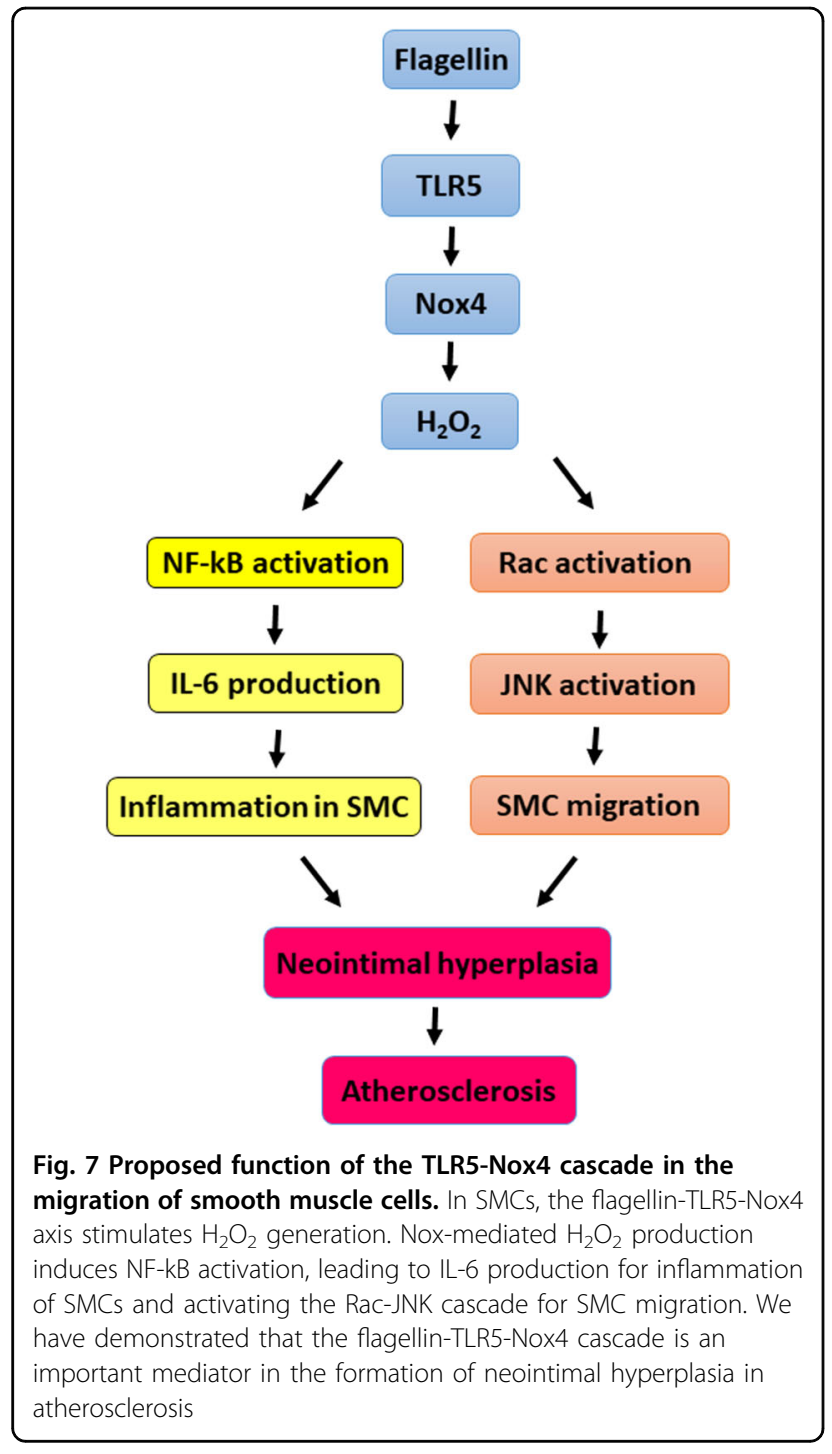

\section{Acknowledgements}

This work was supported by a National Research Foundation of Korea (NRF) grant (No. 2012R1A5A1048236 to YSB), by the Aging Project

(2017M3A9D8062955 to YSB), by a stem cell grant (2017M3A9B3061850 to YSB) funded by the Ministry of Science and ICT, and by a grant from the Korea Health Technology R\&D Project through the Korea Health Industry Development Institute (KHIDI, grant number H115C2800).

\section{Ethics statement}

All animal procedures were approved by the Institutional Animal Care and Use Committees at Ewha Womans University.

\section{Conflict of interest}

The authors declare that they have no conflict of interest.

\section{Publisher's note}

Springer Nature remains neutral with regard to jurisdictional claims in published maps and institutional affiliations.
Supplementary Information accompanies this paper at https://doi.org/ 10.1038/s12276-019-0275-6.

Received: 30 October 2018 Revised: 29 March 2019 Accepted: 10 April 2019.

Published online: 10 July 2019

\section{References}

1. Libby, P., Ridker, P. M., Hansson, G. K \& Ather, L. T. N. Inflammation in atherosclerosis from pathophysiology to practice. J. Am. Coll. Cardiol. 54, 2129-2138 (2009).

2. Gistera, A. \& Hansson, G. K. The immunology of atherosclerosis. Nat. Rev. Nephrol. 13, 368-380 (2017).

3. Libby, P. Inflammation in atherosclerosis. Nature. 420, 868-874 (2002).

4. Erridge, C. The roles of toll-like receptors in atherosclerosis. J. Innate Immun. 1, 340-349 (2009).

5. Lundberg, A. M. \& Hansson, G. K. Innate immune signals in atherosclerosis. Clin. Immunol. 134, 5-24 (2010).

6. Edfeldt, K, Swedenborg, J., Hansson, G. K. \& Yan, Z. Q. Expression of toll-like receptors in human atherosclerotic lesions - a possible pathway for plaque activation. Circulation 105, 1158-1161 (2002).

7. Erridge, C. et al. Vascular cell responsiveness to toll-like receptor ligands in carotid atheroma. Eur. J. Clin. Investig. 38, 713-720 (2008).

8. Lassegue, B., San Martin, A. \& Griendling, K. K. Biochemistry, physiology, and pathophysiology of NADPH oxidases in the cardiovascular system. Circ. Res. 110, 1364-1390 (2012).

9. Bae, Y. S., Oh, H., Rhee, S. G. \& Do Yoo, Y. Regulation of reactive oxygen species generation in cell signaling. Mol. Cells. 32, 491-509 (2011).

10. Park, H. S. et al. Cutting edge: direct interaction of TLR4 with NAD(P)H oxidase 4 isozyme is essential for lipopolysaccharide-induced production of reactive oxygen species and activation of NF-kappa B. J. Immunol. 173, 3589-3593 (2004).

11. Park, H. S., Chun, J. N., Jung, H. Y., Choi, C. \& Bae, Y. S. Role of NADPH oxidase 4 in lipopolysaccharide-induced proinflammatory responses by human aortic endothelial cells. Cardiovasc. Res. 72, 447-455 (2006).

12. Bae, Y. S. et al. Macrophages generate reactive oxygen species in response to minimally oxidized low-density lipoprotein toll-like receptor 4-and spleen tyrosine kinase-dependent activation of NADPH oxidase 2. Circ. Res. 104, 210-U147 (2009).

13. Miller, Y. I., Choi, S. H., Wiesner, P. \& Bae, Y. S. The SYK side of TLR4: signalling mechanisms in response to LPS and minimally oxidized LDL. Br. J. Pharmacol. 167, 990-999 (2012).

14. Lee, J. H. et al. Interaction of NADPH oxidase 1 with toll-like receptor 2 induces migration of smooth muscle cells. Cardiovasc. Res. 99, 483-493 (2013).

15. Kim, J., Seo, M., Kim, S. K. \& Bae, Y. S. Flagellin-induced NADPH oxidase 4 activation is involved in atherosclerosis. Sci. Rep. 6, 25437 (2016).

16. Nam, D. et al. Partial carotid ligation is a model of acutely induced disturbed flow, leading to rapid endothelial dysfunction and atherosclerosis. Am. J. Physiol. Heart Circ. Physiol. 297, H1535-H1543 (2009).

17. Frigault, M. M., Lacoste, J., Swift, J. L. \& Brown, C. M. Live-cell microscopy - tips and tools. J. Cell Sci. 122, 753-767 (2009).

18. Lim, H. J. et al. Function of Ahnak protein in aortic smooth muscle cell migration through Rac activation. Cardiovasc. Res. 97, 302-310 (2013).

19. Durgin, B. G. \& Straub, A. C. Redox control of vascular smooth muscle cell function and plasticity. Lab Investig. 98, 1254-1262 (2018).

20. Fu, D., Xiao, C., Xie, Y., Gao, J. \& Ye, S. MiR-3926 inhibits synovial fibroblasts proliferation and inflammatory cytokines secretion through targeting toll like receptor 5. Gene. 687, 200-206 (2019).

21. Ellenbroek, G. H. et al. Leukocyte TLR5 deficiency inhibits atherosclerosis by reduced macrophage recruitment and defective T-cell responsiveness. Sci. Rep. 7, 42688 (2017)

22. Song, E. J. et al. Flagellin promotes the proliferation of gastric cancer cells via the toll-like receptor 5. Int J. Mol. Med. 28, 115-119 (2011).

23. Hopkins, P. N. Molecular biology of atherosclerosis. Physiol. Rev. 93, 1317-1542 (2013).

24. Clempus, R. E. et al. Nox4 is required for maintenance of the differentiated vascular smooth muscle cell phenotype. Arterioscler. Thromb. Vasc. 27, 42-48 (2007).

25. Zampetaki, A., Zhang, Z. Y., Hu, Y. H. \& Xu, Q. B. Biomechanical stress induces IL-6 expression in smooth muscle cells via Ras/Rac1-p38 MAPK-NF-kappa B signaling pathways. Am. J. Physiol. Heart Circ. Physiol. 288, H2946-H2954 (2005). 
26. Johnson, J. L. Emerging regulators of vascular smooth muscle cell function in the development and progression of atherosclerosis. Cardiovasc. Res. 103, 452-460 (2014).

27. Chistiakov, D. A., Orekhov, A. N. \& Bobryshev, Y. V. Vascular smooth muscle cell in atherosclerosis. Acta Physiol. 214, 33-50 (2015).

28. Hajam, I. A., Dar, P. A., Shahnawaz, I., Jaume, J. C. \& Lee, J. H. Bacterial flagellin-a potent immunomodulatory agent. Exp. Mol. Med. 49, e373 (2017).

29. Xie, Y. F. et al. Treponema pallidum flagellin FlaA2 induces IL-6 secretion in THP-1 cells via the Toll-like receptor 2 signaling pathway. Mol. Immunol. 81, 42-51 (2017).

30. Jeon, J. H. et al. Bacterial flagellin induces IL-6 expression in human basophils. Mol. Immunol. 65, 168-176 (2015).

31. Cho, H. Y. \& Lee, S. W. TLR5 activation by flagellin induces doxorubicin resistance via interleukin-6 (IL-6) expression in two multiple myeloma cells. Cell Immunol. 289, 27-35 (2014).

32. Jiang, C. H. et al. Treponema pallidum flagellins stimulate MMP-9 and MMP-13 expression via TLR5 and MAPK/NF-kappa B signaling pathways in human epidermal keratinocytes. Exp. Cell Res. 361, 46-55 (2017).

33. Castano-Rodriguez, N., Kaakoush, N. O. \& Mitchell, H. M. Pattern-recognition receptors and gastric cancer. Front Immunol. 5, 1-23 (2014).
34. Takahashi, N., Tetsuka, T., Uranishi, H. \& Okamoto, T. Inhibition of the NF-kappa B transcriptional activity by protein kinase A. Eur. J. Biochem. 269, 4559-4565 (2002).

35. Cole, J. E., Kassiteridi, C. \& Monaco, C. Toll-like receptors in atherosclerosis: a 'Pandora's box' of advances and controversies. Trends Pharm. Sci. 34, 629-636 (2013).

36. Loppnow, H., Buerke, M., Werdan, K. \& Rose-John, S. Contribution of vascular cell-derived cytokines to innate and inflammatory pathways in atherogenesis. J. Cell Mol. Med. 15, 484-500 (2011).

37. Lee, G. L. et al. TLR4-activated MAPK-IL-6 axis regulates vascular smooth muscle cell function. Int J. Mol. Sci. 17, 1394 (2016).

38. Kinlay, S. \& Egido, J. Inflammatory biomarkers in stable atherosclerosis. Am. J. Cardiol. 98, 2P-8P (2006)

39. Schieffer, B. et al. Expression of angiotensin $\|$ and interleukin 6 in human coronary atherosclerotic plaques - Potential implications for inflammation and plaque instability. Circulation. 101, 1372-1378 (2000).

40. Ridker, P. M. From C-reactive protein to interleukin-6 to interleukin-1 moving upstream to identify novel targets for atheroprotection. Circ. Res. 118, 145-156 (2016). 